\title{
Article
}

\section{A study on Spinsterhood in Morocco: Students' Attitudes towards Spinsterhood, FLDM, Fez}

\author{
Sofian, Herouach \\ Lettresdm@menara.ma \\ FLDM ( Faculty of Letters and Human Sciences, Dher El Mehrez,Fez) \\ etudesenglaises@outlook.fr; Tel.: +2120617286283
}

\begin{abstract}
:
The present study is an attempt to investigate the factors behind spinsterhood, the sort of perception popular mindset hold on spinsters and the consequences of being a spinster. It starts with a theoretical part as a background to the topic. Then, it moves to the practical part where the study depends a field work for testing the constructed hypothesis. The field work is conducted through distributing quiet a big number of representative questionnaires. Briefly, the findings proved that the majority of respondents, $51 /{ }^{\circ}$ believe that the society considers spinsters as those who had never been proposed to. Moreover, $52 /{ }^{\circ}$ of respondents believes that spinsters are old women who had never been married. Both may imply a negative connotation set by society and culture for unmarried women. As to the factors behind spinsterhood, the findings proved that the majority of the respondents, $75 /{ }^{\circ}$ refer spinsterhood to the fact that women prioritize their education and careers on marriage. For the consequences of spinsterhood, the major result demonstrates that $53 /{ }^{\circ}$ of respondents believe that spinsters' isolation and embarrassment is one major impact of spinsterhood.
\end{abstract}

Keywords: unmarried women, modernity and individuality, education and career priorities, social stigma, social pressure, psychological influences

\section{Introduction}

First of all, it seems of considerable importance to start up with a concise definition for the term Spinster. Spinster is used to refer to an unmarried woman who is older than what is perceived as the prime age range during which women should marry. It could also indicate that a woman was considered unlikely to ever marry (Dictionary, 2016). Spinsterhood has probably existed as long as human history and all over the world, even in Western developed countries. For instance, in Western Europe, high incidence of permanent celibacy and high age at first marriage are the two distinguishing features of Western Europe marriage pattern(T.Engelen \& Kok, 2003). Though a higher percentage of people still enters into heterosexual formal marriage, marriage rates have continued to decline in most developed and developing countries, including those known for conservative marriage culture.

In this study, it is hypothesized that spinsterhood is more likely to be affected by factors such as natural, educational and occupational ones. The present study is an attempt to investigate the factors behind spinsterhood, the sort of perception popular mindset hold on spinsters and the consequences of being a spinster. This paper attempts to answer main questions such as:

a. What are the implications of Spinsterhood 
b. What are the factors behind spinsterhood?

c. What are the impacts of spinsterhood?

I find it of outstanding importance to tackle social issues that are nowadays constantly spread worldwide such as spinsterhood. Moreover, I'd love to add my contribution to this subject, especially knowing that there are few researches that cover this phenomenon so far. Such issues and their effects do reflect real daily life situations and socio- psychological problems that could take place in spinsters' and single people' lives. I find the work worthy of considering because it addresses a social issue; not restricted to the location of the field work or the chosen sample for the study only, but it could concern large masses and communities all over the world. I relied on a general literature (theoretical background) which shows that spinsters may undergo similar situations across several countries of the world, especially the big traditional and underdeveloped part of the world. Moreover, the paper may contribute in understanding in depth the socio- psychological problems that surge up in spinsters lives and therefore sympathize with their cases. Thus, my rationale behind this work flows in this regard and for this purpose.

\section{1: Materials and Methods}

\section{A. Significant Factors and Spinsterhood as a Stigma \\ a. Natural Factors}

It may seem, at first glance, irrational or inapplicable to include natural or biological factors behind spinsterhood as a social phenomenon. However, in traditional societies, natural factors such as beauty, fitness and woman's attractiveness may play important roles in determining woman's marriage or spinsterhood. In Morocco, the criterion of beauty is largely taken in consideration by the spouse and his families (Bihmidine, 2012). The latter claims that physical beauty is a decisive factor to spinsterhood and he adds that we usually find among spinsters only the unattractive women (Bihmidine, 2012)In Moroccan families with girls, Bihimdine(2012) clarifies that whenever a suitor knocks the door to ask for a girl's hand, he usually keeps an eye on the prettiest of the pretty. That is, suitors can be offered several girls to choose from, but they usually tend to choose the most beautiful. It is a bitter reality that girls face when men mercilessly consider beauty as one of the criteria by which they can marry some women and leave the rest to suffer spinsterhood (Bihmidine, 2012).

On the other hand, disabled women are marginalized and distanced from marriage as a consequence of a natural factor. That is, disability victimizes women and deprives them of many rights. Mernissi (1992) debates that in traditional societies; a woman is usually expected to be a good mother inside the marriage relationship. Woman, Mernissi(1992) demonstrates, is supposed to take care of children, do the housework and please her husband sexually. Her being and importance are mainly related to her ability of performing these functions (Mernissi, 1992). Since disabled women are incapable of performing neither of these roles; they are marginalized, neglected and doomed to spinsterhood. As Anderson \&, k. put it "Women's identity in western society is often defined around themes such as reproduction, home-making, and body-image .Disability disrupts these themes» (Kitchin, 2000). Moreover, Anderson \&, k.(2000) claim that cultural representations reinforce the 
stereotypes and lead to more rejection of disabled people. They argue that in modern western societies, disabled people are commonly portrayed as abnormal, child-like, damaged goods, freaks of nature, unattractive, dependent, in need of protection, a danger unto themselves, an object of pity, unproductive and anti-social (Kitchin, 2000)

Sexually arguing, cultural representations consider disabled people as asexual. (Giulio, 2003). The latter announces that cultural representations of disabled people as sick and sexless is supported and sustained by a set of myths. Myths in relation to disability and sexuality include disabled people being asexual. That is, they lack a biological sex drive and are unable to take part in sexual activity. And that disabled people, particularly those with developmental/intellectual disability, lack the requisite social judgment to behave sexually in a socially responsible manner (Giulio, 2003). When these women are regarded sexually and socially unable, they are obviously destined to spinsterhood. Thus, we find that the dominant male ideology and cultural representations of disabled women may be major factor behind spinsterhood.

\section{b. Educational/ Professional Factors}

One of the characteristics of modernization is individualism and families' fractions. A notable impact of modernization is later marriage for both men and women in nearly every non western country. One modernization factor responsible for this universal trend of later marriage is education. For example, a research conducted in Lagos, Negeria, by Ntoimo \&,A.(2008) argues that several spinsters referred to education as personal or perceived reason for marital delay in Lagos (Abanihe, 2008). Moreover, formal education may stand behind marriage delay as women prefer to continue their studies and find a job. Education has been found to affect women's perception of marriage and decisions not to marry in many societies (Abanihe, 2008). The later stress that the length of time education takes inevitably postpones marriage for so many women because they would not marry while attending school. In other words, education refines women's world view and gives them a completely new value about ideal marriage and marriage partner. In the same interest, Alkohali argues that it seems like a rule that if a woman wants to complete her education and work to depend on herself, she will lose her marital life (Alkohali, 2014). This means that, Alkohali adds, the risk of women's rights in educational and public life and in male society is that women fall victim to spinsterhood. Moreover, Alkohali (2014) stresses that once families have begun to realize the importance of education and work, they become more interested to study and be employed, especially in the cities (Alkohali, 2014)

\section{c. Spinsterhood Implcations}

What may remain hardly unbearable is not only the problem of the various factors that may lead to spinsterhood but also and mainly the perception of the community and the weight of culture on the individual when he or she doesn't meet the social norms. Among this, there is the expectation that women ought to get married no later than a certain specified age. Thus, spinsterhood, as a social phenomenon, may carry negative implications in some societies, especially in conservative societies such as Morocco. Zahara (2003) argues that in many societies, to remain unmarried beyond a certain age is regarded as a misfortune. Such women are pitied and blamed for their status and negative stereotypes are associated with their civil 
status (Zahara, 2003). Highlighting the significance of spinsters in traditional societies, Flah (2012) noted:

"When women remain unmarried in an advanced age, they are outcast from the mainstream society. The regular use of words like spinster or Bayra are constant reminders that these women were not up to society's expectations that require women to be physically attractive, compliant with the norms of marriage and most importantly kept under control" (Flah, 2012)

Moreover, a spinster may not only be referred to as a woman who stays unmarried, but words like spinster in English, Aanissa in Arabic or Bayra in Moroccan colloquial may connote negative attributes to these women.

"These words do not depict only the status of women who have not experienced marital relations. They bear a whole aura of negative attributes conducive to antagonistic attitudes towards the women referred to" (Flah, 2012).

The implications of spinsterhood differ from society to another according to the socio-cultural norms. Also, the rate of spinsterhood varies across countries and according to circumstances. Added to gender discrimination, the Socio-cultural rules prevalent in some societies may lie as unsupportable pressures on spinsters as well as its effects increase. That is, the social order in some conservative traditional societies, based on gender discrimination makes it hard for a woman to avert from marriage. In this regard, Flah (2012) says:

"In most conservative societies, the female character at the risk of rejection and social stigma is required to fulfill a number of expectations. Women represent in patriarchal societies the subject of sexual desire, motherhood and virtue. When women fail to fulfill these anticipated attributes, society retaliates mercilessly". (Flah, 2012)

Flah, respectively, points out to the fact that the marital status, based on male dominance, imprisons woman's freedom and liberty. Thus, as an escape from the burdens of marriage, some women decide to stay unmarried. However, these women receive much cultural insulation and symbolic violence from the surrounding people. They are considered against the stream and against the supposedly accepted norms. Flah (2012) confesses that when women remain unmarried in an advanced age, they are rejected from the mercy and benediction of the society. She reiterates that the regular use of words like spinster or Bayra is constant reminders that these women were not up to society's expectations that require women to be physically attractive, compliant with the norms of marriage and most importantly kept under control (Flah, 2012). The socio-cultural orders, based on inequality, father dominance and patriarchal ideologies may create a phobia towards marriage institution. These above mentioned factors; divided between natural and educational ones, added to the negative socio-cultural perception on spinsters may yield unbearable impacts on spinsters.

\section{B. Spinsterhood Impacts}

\section{a. Socio-Cultural Problems}

Generally speaking, whenever there is a phenomenon; it is referred to the causes behind it. The causes, in turn, yield automatic consequences. There may be some positive 
consequences of spinsterhood. Yet the challenges may outweigh the benefits. On one hand, spinsterhood is usually a matter of destiny; it is not always a choice like singleness. On the other hand, spinsters face many cultural burdens. The first expected impact is the problem of social identity. Due to the pervasive concept of motherhood, spinsters find difficulties to construct a positive identity of them. The social and the cultural problems spinsters encounter in their daily life are multiplying. Behmidine(2012) argues that when women stay unmarried for so long, they are instantly rejected by the society and even considered as good for nothing. Still worse, Behmidine stresses, is that in some homes, mothers blame their daughters for remaining spinsters as though they became so of their own accord. Mothers insist that their daughters get married the soonest possible for the trivial reason that spinsterhood has turned out to be an unbearable curse. He puts :

"In the case of sons, it is different. Mothers rarely insist that their sons find a suitable spouse as soon as possible, for no one in society is going to blame them when the sons grow old. What is a real pity is that society sometimes cannot help considering spinsterhood as a sin committed by spinsters". (Bihmidine, 2012)

It is clear from the above citation how spinsters suffer under the cultural norms and the blindly social order which upsurge them in a confusion about themselves, their social identity and their femininity. On the other hand, social depression and constant anxiety could be inevitable impacts of spinsterhood. Eid (2007) puts:

"Most spinsters suffer from anxiety, depression and multiple psychosomatic complaints, including headaches, epigastric disturbances, abdominal gases and discomfort. They tend to be suspicious and they make those around them uncomfortable. They are somehow viewed as abnormal because they do not go through motherhood - spinsters are the object of social pity. They feel they are unfulfilled, incomplete" (Eid, 2007).

The above mentioned quote clearly shows the socio-psychological sufferance of spinsters, especially when stated by a specialist in medicine ( Wafeek Eid). That is, Eid meets usually spinster cases; therefore, his judgment is based on experience.

\section{a. Psychological Impacts}

By most accounts, psychological consequences of spinsterhood are inevitable. The first psychological effect thought about in this study is loneliness and isolation. Loneliness is usually the first matter may be faced by spinsters, especially in traditional societies where spinsters are associated with negative implications. That is because, they are mostly rejected companionship and excluded as they don't meet the socio-cultural norms. On the other hand, spinsters may confront difficult times such as when they fall in a certain illness or when they are met with a certain life hardship that needs collaboration and there is no one to sympathize or help them. Moreover, inadequate finance and sole responsibility for domestic maintenance may aggravate the feeling of loneliness for spinsters and the lonely feeling increases with age (Abanihe, 2008)

Another psychological impact may be ensued is the fear of permanent childlessness and singleness. Ntoimo \&,A.(2008) argue that the fear of permanent singleness and childlessness is found to be a major concern to older never married women. As Ntoimo \&,A.(2008) stress, 
213 they wish (these women) to marry but there is a looming fear that it may not happen 214 (Abanihe, 2008).For example, Ntoimo \&,A.(2008) add, they are(spinsters) usually troubled 215 by the thought of "who will take care of me in old age! Who will inherit my property! And 216 who will bury me"? (Abanihe, 2008). In their conducted research, in Lagos, Nigeria, 217 Ntoimo\&, A. showed the worry of spinsters through interviewing their respondents. For 218 example, one of their respondents said: "But as a woman, I am now feeling it even to my 219 bone. You know why, if i grow old who will take care of me? When will I start having children 220 that will take care of me?" (Female, 46 years old). In the same topic, another respondent 221 said: "No matter what a man or woman possesses, without marriage and children, who will 222 inherit your money?"' (Female, 36 years old). (Abanihe, 2008),Lagos, Nigeria.

Morocco is another traditional society where we can expect similar findings. In Morocco also, spinsters may remain possessed by the idea of motherhood and marriage and may suffer similar society pressure, marginalization and condemning. That is because, like many conservative patriarchal societies, the Moroccan society is based on a social order that may create fear and pressure on the soul of spinsters. Choosing a sample population for examining the attitudes of FLDM students towards Spinsterhood is a field work attempt for further validity and credibility. Even though the sample population is inside the faculty, it could be largely representative of the vast Moroccan population mindset on spinsters and spinsterhood as their attitudes refer to the general culture of the nation. This will be the mission of the second part.

\section{Second Part: Field Work, Findings and Analysis}

\section{Results}

\subsection{Sub-section: Questionnaire Results}

\subsubsection{Sub-section: The Profiles of Spinsters}

First Figure: (a)

- First Item : young woman who has never been married

- Second Item : women who voluntarily choose to be single

- Third Item c: women who want to get married but they cant find a husband

- Fourth Item d: divorced women who don't get married again

- Fifth Item E: old women who had never married

\subsubsection{Sub-section: The Socio-Cultural Mindset on Spinsters}

Second Figure: $(b)$

- First Item: a woman who failed to find a husband

- Second Item: a woman who voluntarily refused to get married

- Third Item: an unlucky woman

- Fourth Item: a woman who has never been proposed to

- Fifth Item: a woman lacking beauty

- Sixth Item: a woman lacking education 


\subsubsection{Sub-section: The factors standing behind spinsterhood}

Third Figure: (c)

- First Item a: families guiding the choices of their daughters and not accepting any man to be their daughter's husband

- $\quad$ Second Item: women getting old and exceeding the age of marriage

- Third Item : the high living costs

- Fourth Item : the unsuccessful marriages that frighten Moroccan women

- $\quad$ Fifth Item : women prioritizing their careers and studies over marriage

- Sixth Item : women not trying to find a husband

- Seventh Item : women refusing to get married with divorced men who have children

- Eighth Item : women refusing to be second/third... wives

\subsubsection{Sub-section : The impacts of spinsterhood}

Fourth Figure: (d)

- First Item : Moroccan society perceives spinsters as losers and poor girls

- Second Item: spinsters feel embarrassed within their families and in the society

- Third Item : having a spinster within a family is considered a shame

- Fourth Item : spinsters are usually accused of being the reason why they couldn't get married

- Fifth Item e: women are threatened by spinsterhood in order to pressure them to get married as soon as possible

- Sixth Item : women are not perceived as complete females unless they are married

- Seventh Item: even though women might have a brilliant career, they are not perceived as successful unless they can find a husband.

\subsection{Sub-section: Figures and Tables.}

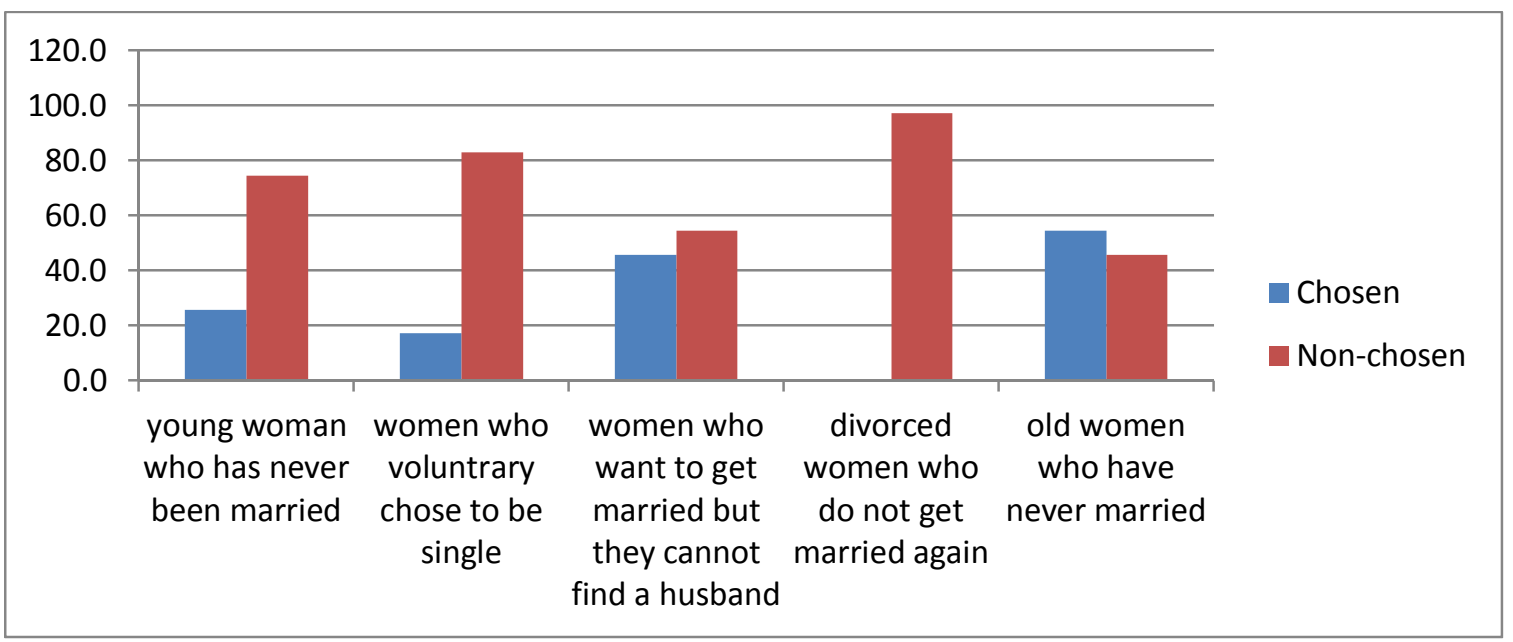

Figure (a): The Profiles of Spinsters

A close analysis of the first figure (figure(a): the profiles of the Spinsters) demonstrates that the majority of respondents, $95 /^{\circ}$, refuse to identify spinsters as women who had been divorced and not married again. Whereas, the majority, $52{ }^{\circ}$; believe that spinsters are old women who had never been married. That is evident as long as culture and society are concerned. Not far from the previous percentage, $82 /^{\circ}$ of the respondents reject that spinsters are those women who voluntarily chose to be singles. On the contrary, a close majority to the previous, $47 /^{\circ}$ identify spinsters as those women who 
wanted to get married and didn't find a husband. This result and significance go hand in hand with the previous one which proved that spinsters are old women who had never been married. On the other hand, $70 /{ }^{\circ}$ of the respondents refuses to portray young women who had never been married as spinsters. Finally, only $18 /^{\circ}$ thinks that spinsters are those who voluntarily choose to be singles. From this analysis, we are getting closer to the perception of a spinster in the Moroccan socio-cultural mentality. This will be analyzed in the next section.

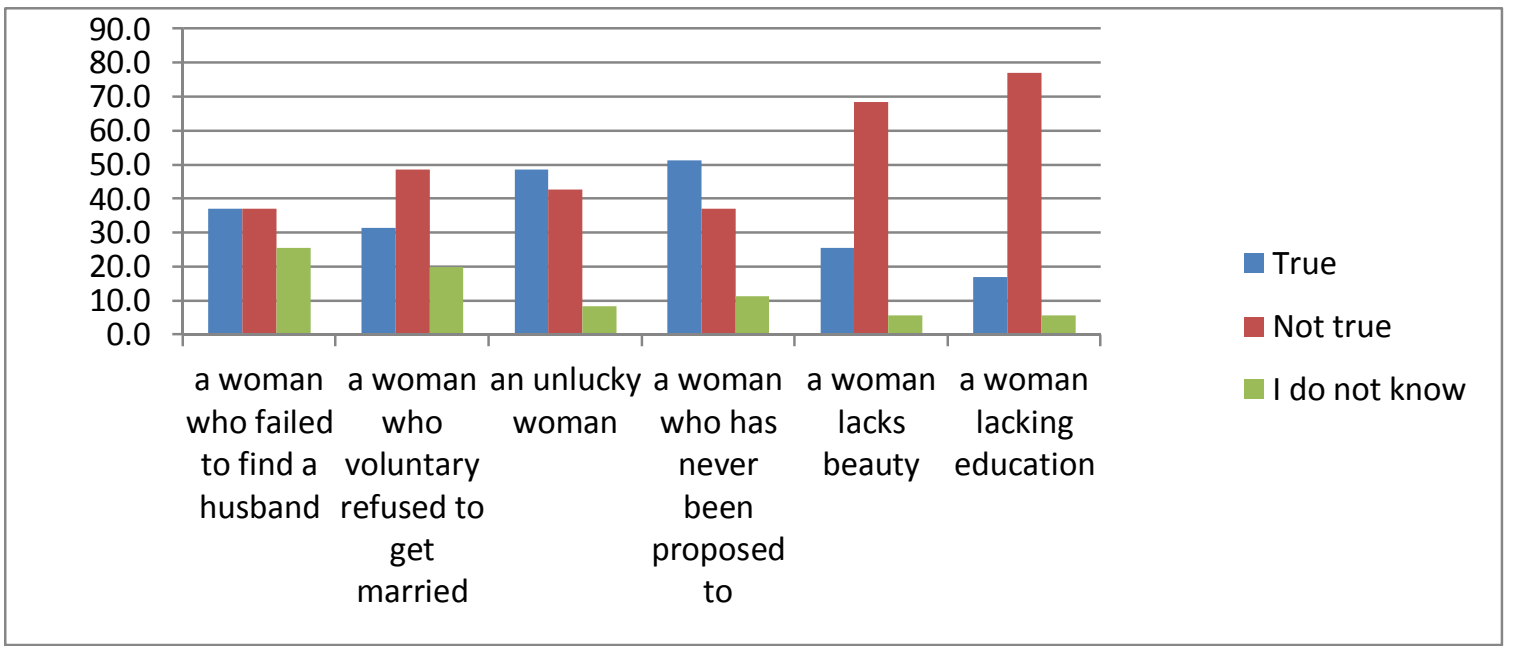

A close analysis of the second figure (Figure $(b)::$ the socio-cultural perception on spinsters) demonstrates that the majority of the respondents, $75{ }^{\circ}$ see the society as not referring spinsters to those women who lack education. Whereas, a majority of respondents, $51{ }^{\circ}$ believe that the society considers spinsters as those who had never been proposed to. That is to say, the society and culture have a strong weight on individuals and on spinsters. Close to the previous percentage, $68 /^{\circ}$ of the respondents views stress that spinsters are not those women who lack beauty. An important percentage, $50 /{ }^{\circ}$ claims that spinsters are unlucky women. In a society based on chances, lack..., it is evident to expect such claims.

\section{Spinsterhood Factors}

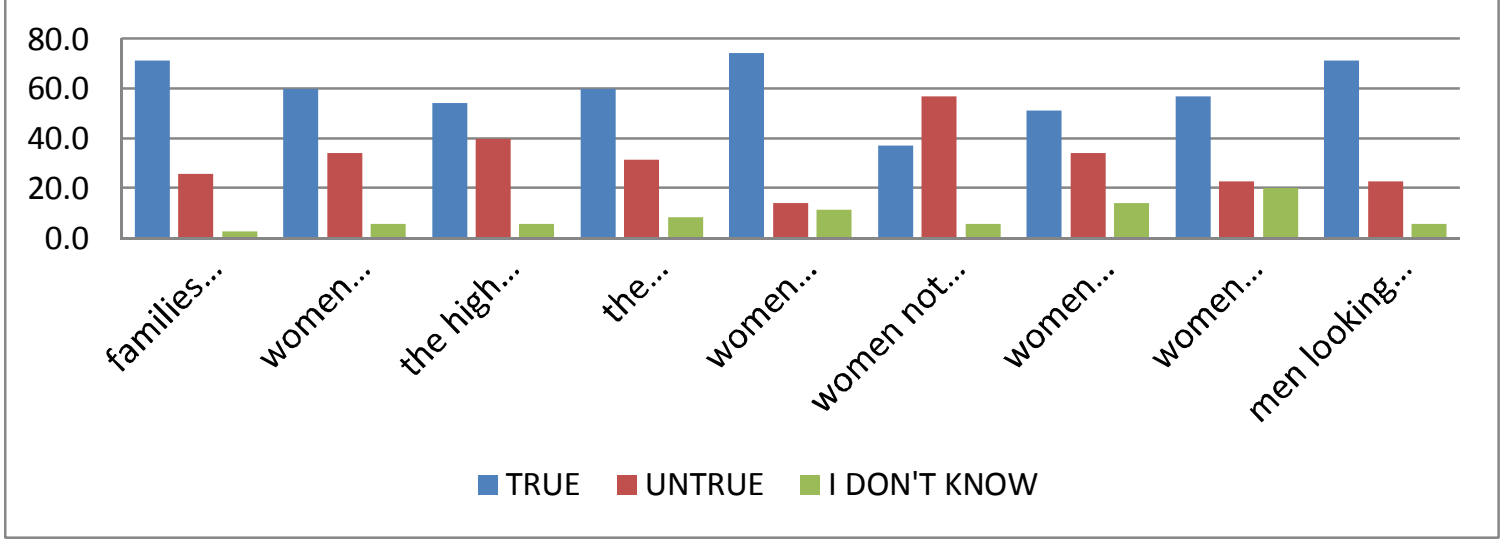


A quick glimpse at the third figure (figure (c) : the factors behind spinsterhood) reveals that the majority of the respondents $75 /^{\circ}$ refer spinsterhood to the fact that women prioritize their education and careers on marriage. This fact is not shocking as the needs of modern time push women to prioritize such choices. This fact is reinforced by a percentage of $70 /{ }^{\circ}$ of the respondents who believe that men's looking for working women is a principal factor towards women's spinsterhood. On the other hand, an important percentage of the respondents, 70/ claim that families control of their daughters choices stand a major reason behind fates such as spinsters. This has to do with the Moroccan culture and patriarchal dominance experienced in Moroccan families. In addition, $60 /{ }^{\circ}$ of the respondents agreed that the fear to fall in unsuccessful marriages prevent women from getting married. Once again, the Moroccan society bears women much difficulty inside the marriage institution which leads to failure. More worthy of mentioning is that $60 /{ }^{\circ}$ of the respondents, as the figure shows, stress that once a woman trespasses a certain age, 35 , she becomes a spinster. It is evident as the society determines certain standards and age for women's marriage. If she trespasses that age, she is doomed to spinsterhood. Finally, $55 /^{\circ}$ of the results proved that the high living costs stand a reason behind spinsterhood. This is not to be neglected as today's reality demands much readiness before one's proposal to marry.

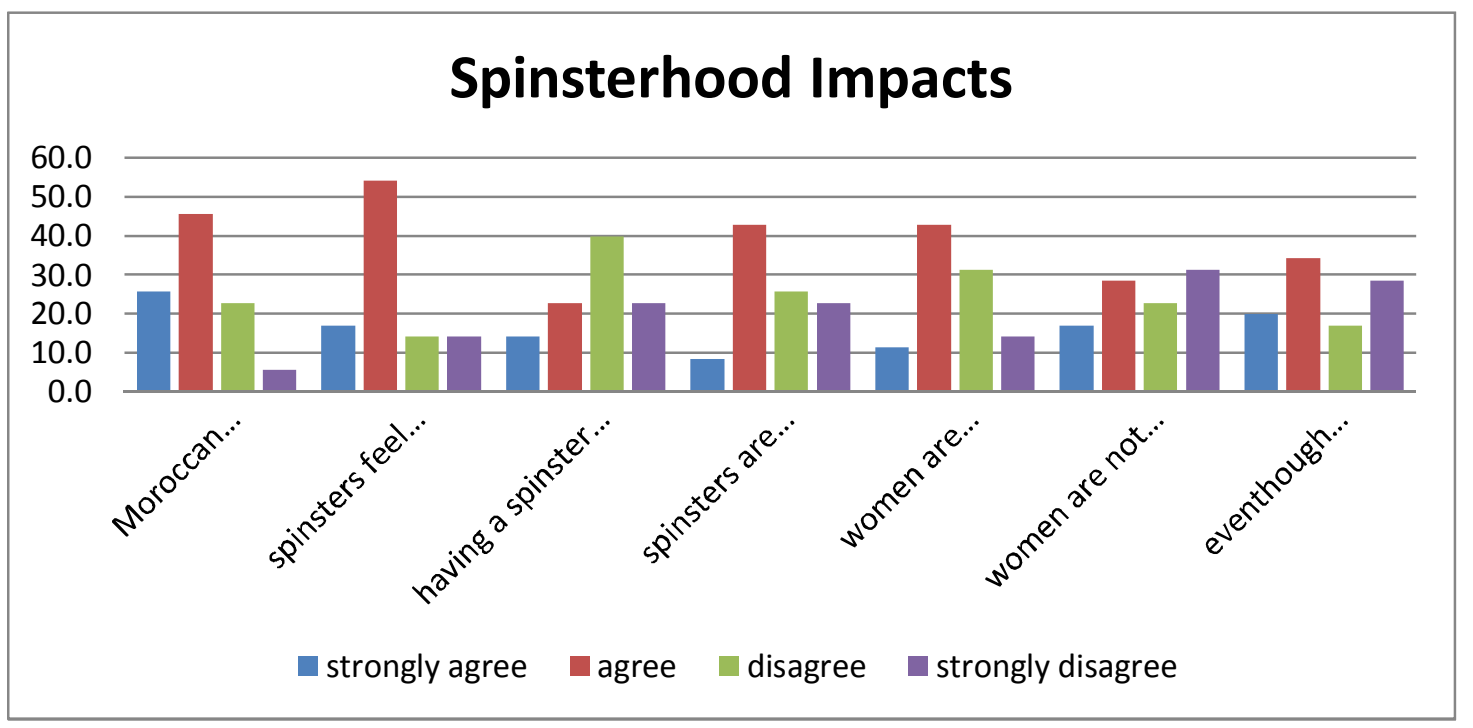

Figure (d): The impacts of spinsterhood

A close analysis of the last figure( figure (d) : impacts of spinsterhood) demonstrates that $53 /^{\circ}$ of the students who were handled out the questionnaires believe that spinsters' isolation and embarrassment is one major impact of spinsterhood. In other words, psychological impacts are unavoidable out of such a phenomenon. That is, society's pressure and culture lead to psychological impacts on spinsters as the latter is unaccepted and damned. Not very far from this percentage, $43 /^{\circ}$ of the respondents believe that the society's consideration of spinsters as failures is a negative impact on spinsters. That is to say, this further creates more psychological problems. Moreover, $42 /{ }^{\circ}$ stresses that the threatening of girls by spinsterhood in order for them to get married as soon as possible is another important impact of spinsterhood. All this shows the significance of marriage in Moroccan patriarchal 
societies. This is further reinforced by $35 /{ }^{\circ}$ of the respondents who claim that despite the fact that women could have a brilliant career they can't be considered successful unless they get married. However, $40 /{ }^{\circ}$ of the respondent disagrees with the claim that a spinster is considered a shame within a family and only $20 /{ }^{\circ}$ who think so. In this regard, the families who may not blame spinsters are very rare.

\section{Discussion}

From the fore- indicated questionnaires, findings and witnesses (look at figures and results), it is crystal clear how spinsters are hold in the popular mindset. That is, the society set rules and norms to relate to, and when these rules are not met, the community exercises influence and pressure on those individuals who are different, deviant and abbreviated. In this regard, spinsters are considered outside these rules; henceforth, society's mercilessness and pressure on them. Concerning the treasons that may lead to spinsterhood as the findings show, they could be either external and beyond one's choice such as natural factors (beauty and attractiveness) or chosen such as education and career priorities .Education is preferred than getting married, henceforth; the increase of spinsterhood. Thus, education is a long process that postpones marriage thoughts. Moreover, once it seems over, though education is always ongoing, a woman thinks about a job, not marriage. Looking for a job after a long process of education is justified by one's ongoing ambitions to be realized. Women, in this regard, neglect the marital side in search of a satisfying work and in hope of achieving economic independence. Yet we can't deny the weight and negative impression on spinsters even when educated. For instance, the third figure results shows that culture and society impact certain sects of the community, particularly, women and the spinsters. In this regard, the social order could be manifested as an oppressive tool against spinsters.

\section{Conclusions}

After a process of investigations, theoretically and practically, we reach that spinsterhood is; by most accounts, a socio-cultural phenomenon. Both, the theoretical and practical part had been in much agreement about the weight of culture and how large it contributes in determining and judging the spinsters image. Briefly, the findings proved that the majority of respondents, $51 /^{\circ}$ believe that the society considers spinsters as those who had never been proposed to. Moreover, $52{ }^{\circ}$ of respondents believes that spinsters are old women who had never been married. Both imply a negative connotation set by society and culture for unmarried women. As to the factors behind spinsterhood, the findings proved that the majority of the respondents, $75 /^{\circ}$ refer spinsterhood to the fact that women prioritize their education and careers on marriage. For the consequences of spinsterhood, the major result demonstrates that $53 /{ }^{\circ}$ of respondents believe that spinsters' isolation and embarrassment is one major impact of spinsterhood.

From the findings, it is evident that spinsters are negatively perceived within the lived community. Despite the variations in answers provided; a general look and comparison proved and agreed to the society's pressure and control of the individual; henceforth, an unbearable pressure on spinsters. In fact, not only are respondents aware of society's burden on the individual, but they also confess the fact that society should be respected and there should be conform to society's norms and rules. That is, the general system should be maintained in esteem. On the other hand, we can't disregard the hard burdens and financial 
361 needs that modernity aggravated, which also contribute to the problem of spinsterhood on a 362 large scale as the findings prove. That is, the economic financial problems and the high 363 costs of living. This also plays a role in leading to spinsterhood. The findings, as above 364 indicated, analyzed also the impacts of spinsterhood on the individual. Usually, spinsters fall 365 in psychological matters due to the fact of staying unmarried. That is, being a spinster 366 engenders a set of pathologies ranging from social depression to isolation from the family and feelings of continuous embarrassment. In other words, marginalization, negligence and 368 the condemning of spinsters become prevalent.

369 Funding: I sincerely declare that this research received no external funding

370 Conflicts of Interest: I sincerely declare that there are no conflicts of interests

$371 \quad$ Appendix

\subsection{Section: Questionnaire Results}

3.1.1. Sub-section: The Profiles of Spinsters

3.1.2. Sub-section: The Socio-Cultural Mindset on Spinsters

3.1.3. Sub-section: The factors standing behind spinsterhood

3.2.1. Sub section: The impacts of Spinsterhood

Sub-section 3.2.2. Figures and Tables.

380 Figure (a): The Profiles of Spinsters

381 Figure (b): The Socio-Cultural Mindset on Spinster

382 Figure (c): The factors standing behind spinsterhood

383 Figure (d): The impacts of spinsterhood

\section{Questionnaire Format}

This questionnaire's aim is to investigate the attitudes towards spinsters, as well as the reasons and consequences of spinsterhood in Morocco.

Very important:

The information you provide will be known only to the author of this questionnaire.

Thank you very much for your help and for the time you will devote to complete this questionnaire

1. Please write as legibly as possible.

2. Please answer all the questions carefully and with precision.

Please complete either by adding the information needed or by ticking the answer that seems to be the most suitable for you. 
2. Female

3. What is your marital status?

400

401

402

403

404

405

406

5. According to you; a spinster is a

$$
\text { What is your field of study? }
$$

1. Language department

2. Psychology

3. Philosophy

4. Sociology

5. Islamic studies

6. Geography and history

2. Married

$\square$

\section{Divorced}

\section{5}

426

427

428

2. Women who voluntary choose to be single

3. Women who want to get married but they cannot find a husband

4. Divorced women who do not get married again

5. Old women who have never been married

6. What is the appropriate age for a woman to get married?

429

1.

18 to $25 \square$

2.

25 to $30 \square$

3.

30 to $35 \square$

4.

Over $35 \square$

430 8. In your opinion, a spinster is more likely to be perceived as

\begin{tabular}{|l|l|l|l|}
\hline Statements & True & Not true & Do not know \\
\hline $\begin{array}{l}\text { A woman who failed to } \\
\text { find a husband }\end{array}$ & & & \\
\hline A woman who & & & \\
\hline
\end{tabular}




\begin{tabular}{|l|l|l|l|}
\hline $\begin{array}{l}\text { voluntarily refused to get } \\
\text { married }\end{array}$ & & & \\
\hline An unlucky woman & & & \\
\hline $\begin{array}{l}\text { A woman who has never } \\
\text { been proposed to }\end{array}$ & & & \\
\hline A woman lacking beauty & & & \\
\hline $\begin{array}{l}\text { A woman lacking } \\
\text { education }\end{array}$ & & & \\
\hline
\end{tabular}

4319 .In your opinion, what are the causes behind spinsterhood?

\begin{tabular}{|l|l|l|l|}
\hline Statements & True & Not true & Do not know \\
\hline $\begin{array}{l}\text { Families guiding the choices of their daughters and not accepting any } \\
\text { Wan to be their daughter's husband }\end{array}$ & & & \\
\hline The high living costs & & & \\
\hline The unsuccessful marriages that frighten Moroccan women & & & \\
\hline Women prioritizing their careers and studies over marriage & & & \\
\hline Women not trying to find a husband & & & \\
\hline Women refusing to get married with divorced men who have children & & & \\
\hline Women refusing to be second/third... wives (Polygamy) & & & \\
\hline costs & & & \\
\hline
\end{tabular}

432 11. To what extent do you agree with the following statements?

\begin{tabular}{|c|c|c|c|c|}
\hline Statements & $\begin{array}{l}\text { Strongly } \\
\text { agree }\end{array}$ & Agree & Disagree & $\begin{array}{l}\text { Strongly } \\
\text { disagree }\end{array}$ \\
\hline \multicolumn{5}{|l|}{ Moroccan society perceives spinsters as losers and poor girls } \\
\hline \multicolumn{5}{|l|}{$\begin{array}{l}\text { Spinsters feel embarrassed within their families and in the } \\
\text { society }\end{array}$} \\
\hline \multicolumn{5}{|l|}{ Having a spinster within a family is considered a shame } \\
\hline \multicolumn{5}{|l|}{$\begin{array}{l}\text { Spinsters are usually accused of being the reason why they } \\
\text { couldn't get married }\end{array}$} \\
\hline \multicolumn{5}{|l|}{$\begin{array}{l}\text { Women are threatened by spinsterhood in order to pressure } \\
\text { them to get married as soon as possible }\end{array}$} \\
\hline \multicolumn{5}{|l|}{$\begin{array}{l}\text { Women are not perceived as complete females unless they are } \\
\text { married }\end{array}$} \\
\hline $\begin{array}{l}\text { Even though women might have a brilliant career, they are not } \\
\text { perceived as successful unless they can find a husband }\end{array}$ & & & & \\
\hline
\end{tabular}


433

434

435

436

437

438

439

440

441

442

443

444

445

446

447

448

449

450

451

452

453

454

455

456

457

458

459

460

462

461 Malay Muslim Women in Malaysia: Preliminary Findings". https://www.researchgate.net .

12. Please feel free to add any additional information

Thank you for your collaboration

\section{Bibliography}

Abanihe, N. \&. (2008). "Determinants of Singlehood: a retrospective account by older single women in Lagos, Nigeria". Researchgate.net .

Alkohali, T. (2014, 3 19). More women workers, more spinsters. Yemen.

Bihmidine, O. (2012). “Spinsterhood: a Choice or a Matter of Destiny?". Morocco's World News.

Dictionary, M.-W. (2016, 7 16). wikimediafoundation.org. Consulté le 7 16, 2018, sur https://en.wikipedia.org: https://en.wikipedia.org/wiki/Spinster\#cite_note-1

Eid, W. (2007). Sad Spinsters: Lonely Hearts. https://gulfnews.com .

8 Flah, L. (2012). Bayrat' or 'Spinsters', Single Women Trapped in Social Stigma. https://www.moroccoworldnews.com .

Giulio, G. D. (2003). Sexuality and People Living with Physical or Developmental Disabilities. The Canadian Journal of Human Sexuality, Vol.12(1) .

2 Kitchin, P. A. (2000). Disability, space and sexuality: access to family planning. Maynooth, 553 University Street, Belfast BT7 1HP, Northern Ireland, UK, National University of Ireland,

54 Maynooth, County Kildare, IrelandIreland. Récupéré sur

55 http://eprints.maynoothuniversity.ie.

56 Mernissi, F. (1992). Islam and Democracy: Fear of the Modern World. New York: /

57 Addison-Wesley.

T.Engelen, J., \& Kok. (2003). "Permanent Celibacy and Late Marriage in the

60 Zahara, R. §. (2003). "Understanding Singlehood from the Experiences of Never-Married 